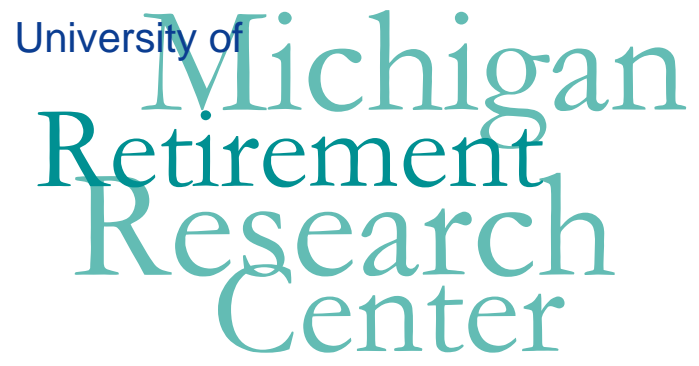

Working Paper WP 2006-134

A Dynamic Model of Retirement and Social Security Reform Expectations: A Solution to the New Early Retirement Puzzle

Hugo Benitez-Silva, Debra S. Dwyer, and Warren C. Sanderson

\begin{tabular}{|l|l|l|l|l|l|l}
\hline $\mathrm{M}$ & $\mathrm{R}$ \\
\hline $\mathrm{R}$ & $\mathrm{C}$ & Project \#: UM06-17 \\
\hline
\end{tabular} 


\title{
“A Dynamic Model of Retirement and Social Security Reform Expectations: A Solution to the New Early Retirement Puzzle”
}

\author{
Hugo Benitez-Silva \\ SUNY-Stony Brook \\ Debra S. Dwyer \\ SUNY-Stony Brook \\ Warren C. Sanderson \\ SUNY-Stony Brook
}

October 2006

\author{
Michigan Retirement Research Center \\ University of Michigan \\ P.O. Box 1248 \\ Ann Arbor, MI 48104 \\ http://www.mrrc.isr.umich.edu/ \\ (734) 615-0422
}

\section{Acknowledgements}

This work was supported by a grant from the Social Security Administration through the Michigan Retirement Research Center (Grant \# 10-P-98358-5). The findings and conclusions expressed are solely those of the author and do not represent the views of the Social Security Administration, any agency of the Federal government, or the Michigan Retirement Research Center.

\section{Regents of the University of Michigan}

David A. Brandon, Ann Arbor; Laurence B. Deitch, Bingham Farms; Olivia P. Maynard, Goodrich; Rebecca McGowan, Ann Arbor; Andrea Fischer Newman, Ann Arbor; Andrew C. Richner, Grosse Pointe Park; S. Martin Taylor, Gross Pointe Farms; Katherine E. White, Ann Arbor; Mary Sue Coleman, ex officio 


\title{
A Dynamic Model of Retirement and Social Security Reform Expectations: A Solution to the New Early Retirement Puzzle
}

\author{
Hugo Benitez-Silva, Debra S. Dwyer, and Warren C. Sanderson
}

\begin{abstract}
The need for Social Security Reform in the next years is hardly a matter of debate. Therefore, the widespread believe among Americans that Social Security will not be able to pay benefits in the long run at the level that was anticipated, does not come as a surprise. The government acknowledges the situation, and predicts that substantial benefits cuts will be necessary, yet no legislation has been passed to tackle the problem. Researchers, however, have rarely modeled the uncertainty over Social Security reform and benefit levels, and how they affect claiming behavior and retirement. The purpose of this paper is to assess the extent to which these perceptions of future cuts might explain the puzzle of earlier take-up despite bigger penalties to doing so in the presence of increasing longevity. By introducing a small amount of uncertainty (based on selfreported responses to questions regarding expectations over future cuts) of a relatively small cut (compared with what the government reports as necessary to solve the crisis) in a dynamic life-cycle model of retirement, we are able to match the claiming behavior observed in the data, without relying on heterogeneous preferences. Our results support the hypothesis that expectations over future benefits are affecting current behavior. We find that a mis-specified dynamic retirement model would erroneously predict that an increase in the NRA would delay claiming behavior and increase labor supply at older ages. Once the appropriate earnings test incentives are modeled, and we account for the probability of reforms to the system, an increase in the NRA has little effect on claiming behavior, and it can even increase the proportion of individuals claiming before the NRA.
\end{abstract}

\section{Authors' Acknowledgements}

We are grateful to a number of employees of the Social Security Administration who have patiently answered our questions. Among those individuals we are especially thankful to Barbara Lingg, Christine Vance, and Joyce Manchester for their time, and for their insights into a number of the issues discussed in this paper. We are grateful to MRRC for the financial support through grant UM06-17. Benitez-Silva is also grateful for the financial supportfrom the Spanish Ministry of Science and Technology through project number SEJ2005-08783-C04-01, and to the Fundacion BBVA. 


\section{Introduction}

Since the 1970s, Social Security Reform has been high on the radar of economic researchers and policy makers in terms of issues of importance. In fact, the 1983 Amendments where meant to solve the financial crisis that Social Security was headed for. For example, President Reagan, in his statement after signing the legislation, stated "Our elderly need no longer fear that the checks they depend on will be stopped or reduced. These amendments protect them. Americans of middle age need no longer worry whether their career-long investment will pay-off. These amendments guarantee it." Within a decade of those words, it became clear that further reforms will be necessary to maintain the long-run balance of the system, given the evolution of the trust fund, and the trends in claiming behavior and labor supply of older Americans. Policy evaluation researchers failed to accurately predict the responses to this increase in the retirement age, suggesting the models used for analysis were misspecified, and ambiguous theoretical responses to such incentives were not properly analyzed, and what might have been considered large nominal cuts to benefits at the time were in fact much smaller in real terms, especially given the large delays embedded in the implementation of the legislation.

This situation has resulted in the widespread believe that Social Security will not be able to pay benefits in the long run at the level that was anticipated. ${ }^{1}$ The government acknowledges the situation, and predicts that substantial benefits cuts will be necessary, yet no legislation has been passed to tackle the problem. ${ }^{2}$ It should not be surprising, therefore, that in the meantime,

\footnotetext{
1 Public pensions are a major income source for older Americans. Under the Old Age and Survivor Insurance (OASI) system, the Social Security program that pays benefits to eligible workers (and their survivors) who claim their benefits, 40 million individuals received about $\$ 435.4$ billion in benefits in 2005 . In that same year around 159 million individuals had earnings covered by Social Security and paid payroll taxes. Under the current system, the early retirement age is 62, and the NRA will gradually increase from the current 65 years and eight months to 67 for cohorts born between 1942 and 1960 and thereafter.

2 The government states that “Under the current system, today's 30-year-old worker will face a $27 \%$ benefit cut when he or she reaches normal retirement age.” In http://www.whitehouse.gov/infocus/social-security/ Strengthen-
} 
the average American approaching retirement age believes (as reported in several waves of the Health and Retirement Study) that there is a $60 \%$ chance that in the next 10 years Social Security benefits will be reduced.

Researchers, however, have rarely modeled the uncertainty over Social Security reform and benefit levels, and how they affect claiming behavior and retirement. ${ }^{3}$ A large literature during the 1980s and 1990s focused on explaining the connection between retirement incentives and retirement behavior, and quite convincingly concluded that the retirement peaks at age 62 and age 65 could be explained if the full set of incentives were included in the model. However, in the data used in those studies the majority of Americans were claiming benefits at age 65, while in the 1980s and 1990s the peak started to move towards age 62. By the end of the 1990s, almost $60 \%$ of older Americans were claiming benefits at age 62, and it has stayed at that level, even with the implementation of the 1983 Amendments that penalize early claiming of benefits and the substantial increase in expected longevity since the 1970s. In fact, as of August, 2006, 70.5\% of men and $75.5 \%$ of women claimed Social Security benefits before the Normal Retirement Age (NRA), compared to $36 \%$ and $59 \%$ in 1970 , respectively. ${ }^{4}$ Clearly, the economic incentives seem to be insufficient to achieve the objective of prolonging average work lives, given the strong correlation between claiming behavior and labor supply.

ing Social Security for Future Generations, Feb, 2005—background and presidential action. In SSA's website similar statements are made. Even influential independent policy makers like Alan Greenspan in front of the Committee of the Budget of the U.S. House of Representatives stated that "Under current law, and even with the so-called normal retirement age for Social Security slated to move up to 67 over the next two decades, the ratio of the number of years that the typical worker will spend in retirement to the number of years he or she works will rise in the long term. A critical step forward would be to adjust the system so that this ratio stabilizes."

${ }^{3}$ One important exception is the work of Bütler (1999), who presents a fifteen periods Overlapping Generations model that analyzes the effects of expected and unexpected reforms, and also Phelan (1999), who discusses more realistic characterizations of that model. One important difference between that work and ours, is that we want to analyze the behavioral effects at the individual level, of reform expectations that do not necessarily materialize in the short to medium run.

${ }^{4}$ See the Social Security Bulletin, OASDI Monthly Statistics, 1970 - 2006. 
The purpose of this paper is to assess the extent to which these perceptions of future cuts might explain the puzzle of earlier take-up despite bigger penalties to doing so. If further cuts are anticipated, then individuals may be weighing in early certain benefit amounts against expected reductions in the amount should they postpone retirement.

We show that one of the keys to appropriately modeling the complex incentive structure of the US Old Age Benefits system is to account for the Earnings Test that directly impact claiming and labor supply between the Early Retirement Age (ERA) and the NRA. Most researchers, have only focused on the taxation aspects of the Earnings Test (ET) provisions, and have not properly modeled the actuarial fairness of the system. Even the most sophisticated dynamic models of retirement have failed to explain the large proportion of Americans claiming early retirement, without making difficult to test and justify assumptions regarding preferences for early retirement. We find that by accounting for the full set of incentives of the ET we get closer to matching the take-up rate in the data. These latter results are in line with the findings of Benítez-Silva and Heiland (2006b). However, our main contribution is the addition of reforms expectations, which we modeled as uncertainty over benefit levels if benefit take-up is delayed. By introducing a small amount of uncertainty (based on self-reported responses to questions regarding expectations over future cuts) of a relatively small cut (compared with what the government reports as necessary to solve the crisis) we are able to match the claiming behavior observed in the data, without relying on heterogeneous preferences. ${ }^{5}$ Our results support the hypothesis that expectations over future

\footnotetext{
${ }^{5}$ Gustman and Steinmeier (2002b) use a dynamic life cycle model that varies rate of time preference across individuals and their predictions come closer to actual than others have found. They measure rate of time preference using accumulated assets (savings) — under the strong assumption that those with higher rates would have saved less. They use this model to simulate an increase in the earliest age of take-up by 2 years and show that the bunching moves to 64-which would be predictable regardless given eligibility rules will restrict the behavior in that way. Those who save less may have higher rates of time preference that drives their otherwise irrational desire to retire earlier. In this case there is little policy can do to prolong work other than mandates of no benefits prior to some age as simulated in that model. Clearly there would be a welfare loss associated with such a (likely regressive) policy. If it is the case that policies with more information can influence behavior in desired directions without such welfare
} 
benefits are affecting current behavior.

Any analysis of the effects of Social Security reforms should be performed within a model that can explain early take-up behavior, and does it by first focusing on accounting for the full incentive structure. We find that a misspecified dynamic retirement model would erroneously predict that an increase in the NRA would delay claiming behavior and increase labor supply at older ages (see Gustman and Steinmeier 1985, for an early discussion of the possible consequences of the 1983 reforms). This kind of rationale seemed to have motivated (and still continues to motivate, rather surprisingly given the inadequate results of previous similar reforms) advocates of reforms to the SSA system, which hoped to obtain additional financial relief to the Social Security system from the taxes obtained through the increase in the work lives of later claimers.

Once the appropriate ET incentives are modeled, and we account for the probability of reforms to the system, an increase in the NRA has little effect on claiming behavior, and it can even increase the proportion of individuals claiming before the NRA. This suggests that any policy that does not affect the ratio between the benefits received at different ages (for example, any further increases in the NRA, which are nothing but benefits cuts affecting all claiming ages equally) should not be expected to have much impact on claiming behavior, and therefore relatively little is to be expected in terms of labor supply responses.

Section 2 provides additional background on retirement incentives and claiming behavior. Section 3 discusses Social Security reform expectations. Section 4 describes the dynamic structural model we use to analyze the impact of uncertainty over Social Security reform, and the consequences of changes in the NRA. Section 5 presents the results of the simulations of the

losses, those policies would be preferred. Notice that given the well known lack of non-parametric identification of dynamic structural models (See Rust 1994, Taber 2000, and Magnac and Thesmar 2002), the reliance on preference heterogeneity to explain behavior is less desirable than being able to account for it through the appropriate incentives, or even empirically grounded homogeneous beliefs about future events affecting economic constraints. 
model, and discusses the policy implications of our findings. Section 6 concludes with a short discussion of policy alternatives.

\section{The Old Age Benefits Incentive System}

Social Security provides fairly complex incentives that affect the labor supply and benefit uptake behavior of individuals between the early retirement age and the maximum retirement age. These incentives are especially involved between the early and normal retirement ages, and we analyze them in detail in the Appendix. Two of the most important incentives are the Social Security Earnings Test, which determines the maximum level of earnings that do not result in a benefit reduction for individuals who have claimed retirement benefits before the NRA, and the Actuarial Reduction Factor (ARF), which determines the permanent reduction in benefits that individuals face if they claim benefits early. However, the role of the Earnings Test in the context of the adjustment of the ARF is not very well understood, or even known.

Although researchers have occasionally documented these fairly complex incentives, they have paid relatively little attention to the possible consequences of these provisions for labor supply and claiming behavior of early retirees. ${ }^{6}$ The existing research has primarily focused on the taxation aspects of the Earnings Test. ${ }^{7}$ Since the removal of the Earnings Test in the year 2000 for those above the NRA, there has been relatively little discussion of the Earnings Test for younger retirees, despite the fact that the arguments used against the former Earnings Test also apply to this case. In fact, the incentives provided by the Earnings Test for early retirees have remained

\footnotetext{
${ }^{6}$ Gustman and Steinmeier (1991), Myers (1993, p. 52), and Gruber and Orszag (1999, 2000) discuss this mechanism in some detail.

7 See Vroman (1985), Burtless and Moffitt (1985), Honig and Reimers (1989), Leonesio (1990), Reimers and Honig (1993), Reimers and Honig (1996), Friedberg (1998), Baker and Benjamin (1999), Friedberg (2000), and Votruba (2003).
} 
essentially unchanged in the last three decades, but with a larger fraction of Americans retiring early, these incentives have become increasingly important. The literature has not analyzed the implications for labor supply and claiming behavior, of the possibility to affect the Actuarial Reduction Factor by working after claiming benefits and earning above the Earnings Test limit. We will show through our dynamic model that the appropriate modeling of these incentives is key in order to understand the claiming behavior of Older Americans.

Table 1, using data from Table 6.A4 of SSA's Statistical Supplement, presents a snapshot of not only an increase in early take-up since the 1970s, but how prevalent take-up at the earliest age of 62 has become. The peaks are at the eligibility ages of 62 and 65 which, comes as no surprise given this well established response to program incentives. Between 1999 and 2005, almost 60\% of claimants have been taking their benefits at age 62 . Roughly $20 \%$ wait for the normal age of retirement. A majority of the remaining $20 \%$ retire between ages 62 and 65 . Notice the rather anomalous claiming behavior in 2000 , which resulted in an increase in claiming at age 65 , and a reduction of the proportion of individuals claiming at 62 . This is entirely driven by the large increase in new entitlements in that year, possibly the product of the removal of the Earnings Test for those above the NRA.

Table 2, also using data from the Statistical Supplement, shows recent trends in benefits received, in dollars of 2005, as a function of the age at which benefits where claimed. We see a clear break in the patterns after 2000. In 1999 and 2000 it can be observed that later claiming lead to consistently larger benefits, while since then the maximum benefit is systematically obtained by those claiming at 65 , but it drops for those claiming after that, maybe because those individuals are now of a type trying to catch up to compensate for a low wage career, or a sketchy one. It is likely that the removal of the ET for those above the NRA had the effect of allowing 
people to claim benefits independently of their labor supply behavior, leading relatively well-off individuals, who before waited to claim to avoid the ET, to claim sooner. Notice that the scheduled increases in the NRA are essentially bringing back the old ET for those above age 65, so the prediction is that a pre-ET-reform benefit level distribution is likely to emerge in the next years.

\section{Social Security Reform Expectations}

What the public debates on the need for Social Security Reform have certainly accomplished is to incorporate uncertainty over future Social Security benefit amounts, despite the increasing amount of information being provided regarding ones benefit amounts under current rules (Mastrobuoni, 2006). While it is true that individuals are better informed now than ever about how much they should expect to get under current rules given the start of regular mailings containing that information, people expect that these benefits are subject to change. And they know the direction of the change, one way or another benefits will be cut.

If further cuts are anticipated, then individuals may be weighing in early certain benefit amounts against expected reductions in the full amount should they postpone retirement. At the margin, we would expect people to continue to retire earlier despite cuts, if they expect the gain to waiting it out to be declining and possibly approaching zero.

To illustrate the mechanism we believe is at play regarding Social Security reform expectations, imagine two individuals with identical Primary Insurance Amounts (PIAs). One of them expects to receive a given amount upon retirement at age 65 with certainty, while the other believes that there is a reasonable probability (could be quite small) of the benefit amount to decline for retirement at age 65 by the time he reaches that age. The incentives to hold out for the full 
benefit amount, at the margin, are higher for the person who believes the payoff is a certain amount. So if individuals believe there is some risk associated with holding out, they might opt out earlier. This would mean that policies to cut benefits and reduce dependency ratios are not realizing desired effects, unless they are perceived as completely solving the financial crisis of the system, otherwise concerns over solvency are likely to continue.

Other plausible explanations for the trends toward earlier claiming of benefits, include increased longevity but worsened functional capacity for work (health as a taste shifter toward leisure), and an increased demand for leisure over time that offsets the higher price of leisure so that empirically it appears to be a Giffen good. Other studies have taken these approaches and, we incorporate these incentives in our dynamic model of retirement benefit take-up, as will be clear from the next section.

In terms of the numbers actually used to reflect the probability of a drop in benefits, we use the ten year panel available through the Health and Retirement Study (HRS), and examine responses to questions regarding expectations over future benefits between the years of 1992 and 2002 . The responses reveal perceptions of a $60 \%$ probability, on average, of benefits becoming less generous within the next 10 years from individuals who began the survey at the pre-retirement eligibility ages of 51 to 61 . The cumulative probability of that happening in a period of 10 years implies a $4.825 \%$ expectation of a drop in the next year. The HRS asked questions regarding the propensity for Social Security to make benefits less generous on a scale of 1 to 10 . In the later years the question was altered slightly to add a time frame-some time in the next 10 years. This did not significantly alter the results. Given the magnitude of these responses, uncertainty over future benefits is warranted in our models of benefit take-up.

In terms of the size of the benefit cut people believe could occur, if we were to follow the 
recent report by the Trustees of the SSA, in order to maintain solvency in the long-run the cuts should be of around $13 \%$ of benefits in real terms. Individuals are likely responding to a more modest cut, predicting that the necessary burden will likely spread across cohorts. We assume individuals believe a permanent cut of $5.75 \%$ of benefits could occur, which is roughly equivalent to about a one year loss in benefits for the average person, which might be a reasonable expectation for the average person. ${ }^{8}$

\section{The Dynamic Model}

The model used in this paper is closely related to those presented in Rust and Phelan (1997), and Benítez-Silva, Buchinsky, and Rust (2003 and 2006). Rust and Phelan (1997) did not model consumption and savings decisions, but did estimate the parameters of the model, using a Nested Fixed-Point algorithm, instead of calibrating them. Benítez-Silva, Buchinsky, and Rust (2003 and 2006) present the most closely related models, which are calibrated to match aggregate data and household level data from the Health and Retirement Study, and model the Social Security Disability Insurance decisions on top of the OASI incentives. Unlike the structural model developed in the present paper, these earlier models (or any other structural models we are aware of) do not explicitly accounted for the possibility of affecting the Actuarial Reduction, or the possibility of expecting a possible benefit cut in the future. Our model also shares a number of characteristics with the work of French (2005), van der Klaauw and Wolpin (2005), and Blau (2004) among other researchers who solve, simulate, and in some cases estimate, dynamic retirement models under uncertainty.

\footnotetext{
8 The qualitative results we will present in the next sections are robust to the assumptions regarding probability of the drop, and the size of the drop. Quantitatively, however, they are robust as long as higher drops are expected with slightly smaller probabilities, and vice-versa.
} 
We assume that individuals live a maximum of 100 years, and face mortality probabilities similar to those in the population. They start their working lives at age 21 , and maximize the expected discounted stream of future utility, where the per period utility function $u(c, l, h, t)$ depends on consumption $c$, leisure $l$, health status $h$, and age $t$. We specify a utility function for which more consumption is better than less, with agents expressing a moderate level of risk aversion. The flip side of utility of leisure is the disutility of work. We assume that the utility (disutility of work) is an increasing function of age, is higher for individuals who are in worse health than individuals who are in good health, and is lower for individuals with higher human capital measured by the average wage. In addition, we assume that the worse an individual's health is, the lower their overall level of utility is, holding everything else constant. Moreover, we assume that individuals obtain utility from bequeathing wealth to heirs after they die. This model assumes that individuals are forward looking, and discount future periods at a constant rate $\beta$, assumed here to be equal to 0.96 . The model also allows for a variety of sources of uncertainty, like lifetime uncertainty, health uncertainty, wage uncertainty, and more importantly, Social Security benefits level uncertainty.

We will see in the next section that the latter is essential to match the large peak of benefits claiming at age 62. Notice, however, that within the model, this uncertainty is never realized, and benefits are never cut, but the existence of a small probability of the event happening affects behavior, and results in claiming benefits earlier, consistently with the empirical evidence.

Any person who is not already receiving Social Security Old Age benefits is eligible to apply for OASI benefits. ${ }^{9}$ Individuals with at least 40 quarters of earnings covered for OASI before

\footnotetext{
9 We are abstracting from Social Security Disability Insurance (SSDI), a program that allows workers with severe disabilities to receive Social Security benefits before the NRA. This program currently covers about 7 million Americans. See Benítez-Silva, Buchinsky, and Rust (2003 and 2006) for a life-cycle model of retirement and SSDI application.
} 
reaching their $62^{\text {nd }}$ birthday are eligible to apply and benefit award is guaranteed. In the present version of the model we allow decisions to be made on an annual basis and assume no lag between application date and date of first receipt.

Calculation of benefits and the reduction factors are as explained in the Appendix on incentives for early retirement, assuming a NRA of 66. In particular the number of checks received in a year depends on the earnings after claiming: the number of checks (or the benefit amount on some checks received towards the end of the period) are reduced reflecting the $50 \%$ rate on labor incomes exceeding the Earnings Test limit between 62 and the January of the year a person turns $66(33 \%$ thereafter). In other words, adjustments to benefits and ARFs occurs in accordance with the earnings and the Earnings Test limit, and we do not consider the possibility that beneficiaries ask Social Security for a reduction of benefits or return benefits received. Even though we set up an annual decision-making process, the Social Security Earnings Test is enforced semiannually, i.e. the benefits received by a beneficiary are adjusted, after reaching the NRA, for the earnings in excess of the Earnings Test limit, as long as six months or more, of benefits were withheld in the years between the early and normal retirement ages. The structure and the details of the model are described below.

\subsection{Model Details}

We solve the dynamic life-cycle model by backward induction, and by discretizing the space for the continuous state variables. ${ }^{10}$ The terminal age is 100 and the age when individuals are assumed to enter the labor force is 21 . Prior to their $62^{\text {nd }}$ birthday, agents in our model make a leisure and consumption decision in each period. At 62 and until age 70, individuals decide on

\footnotetext{
${ }^{10}$ See Rust (1996), and Judd (1998) for a survey of numerical methods in economics.
} 
leisure, consumption, and application for OASI benefits, denoted $\left\{l_{t}, c_{t}, s s d_{t}\right\}$, at the beginning of each period, where $l_{t}$ denotes leisure, $c_{t}$ denotes consumption, which is treated as a continuous decision variable, and $s s d_{t}$ denotes the individual's Social Security benefit claiming decisions.

After age 70 is assumed that all individuals have claimed benefits, and again only consumption and leisure choices are possible. Leisure time is normalized to 1 , where $l_{t}=1$ is defined as not working at all, $l_{t}=.543$ corresponds to full time work, and $l_{t}=.817$ denotes part-time work. These quantities correspond to the amount of waking time spent non-working, assuming that a full-time job requires 2000 hours per year a part-time job requires 800 hours per year. We assume two possible values for $s s d_{t}$. If $s s d_{t}$ equals 1 the agent has initiated the receipt of benefits. If the individual has not filed for benefits or is not eligible then $s s d_{t}$ is equal to 0 .

If benefits are claimed before the NRA the monthly benefit amount is calculated similar to equation (9). For a NRA of 66 years the reduction factor if claimed at 62 is $75 \%, 80.0 \%$ if claimed at $63,86.67 \%$ if claimed at 63 , and $93.33 \%$ if claimed at 65 . Due to the Earnings Test, benefit initiation between the ERA and the NRA does not necessarily imply benefit receipt, nor is the reduction in the benefit rate necessarily permanent after the NRA as a result of the adjustment of the ARFs as discussed in the Appendix (see equation (10)). In particular, we use an annual Earnings Test limit of $\$ 12,480$ between 62 and 65 and $\$ 33,240$ between 65 and 66 (these numbers reflect the 2006 limits). In the former period benefits are reduced at a rate of $\$ 1$ per $\$ 2$ of earnings above the limit and $\$ 1$ per $\$ 3$ of earnings above the limit for the latter period. These are the correct rules for someone who turns 66 in December. Since those whose birthday is earlier in the year face the higher limit and lower tax rate for less than a year (January to month of birthday) we have also simulated two alternative versions, one with the $\$ 12,480$ limit throughout, and another using $\$ 20,760$, the midpoint between the two limits and a tax rate of 50\%. The results of these models 
do not differ markedly from those presented in the paper and are available from the authors upon request. Those claiming after 66 earn the delayed retirement credit. We model it following the rates faced by the 1943-1954 cohorts, of 2/3 of $1 \%$ for each month not claimed between age 66 and 70 .

We also incorporate a detailed model of taxation of other income, including the progressive federal income tax schedule (including the negative tax known as the EITC - Earned Income Tax Credit), and state and local income, sales and property taxes. Individuals whose combined income (including Social Security benefits) exceeds a given threshold must pay Federal income taxes on a portion of their Social Security benefits. We incorporate these rules in our model as well as the $15.75 \%$ Social Security payroll tax.

The model allows for four different sources of uncertainty: (a) lifetime uncertainty: modeled to match the Life Tables of the United States with age and health specific survival probabilities; (b) wage uncertainty: modeled to follow a log-normal distribution, function of average wages as explained in more detail below; (c) health uncertainty: assumed to evolve in a Markovian fashion using empirical transition probabilities from a variety of household surveys, including the NLSY79 and the HRS. The random draws to simulate these three sources of uncertainty are the same for all the models compared in this paper, such that the differences presented in the results are only due to the changes in the incentive schemes.; (d) Social Security benefit level uncertainty: this is one of the main contributions to the paper and we explain it in detail below.

Regarding the latter type of uncertainty, we first assume that agents believe there is a chance of benefits being cut in the future. Second, at age 62 they believe that if they do not claim benefits then there is a small probability of those benefits being smaller in the future. These beliefs are never realized in the simulations of the model, but are present in the expectations of the agents, 
resulting in possible changes in behavior. As explained in the previous section, we use reasonable parameter values based on aggregate data and household surveys.

The state of an individual at any point during the life cycle can be summarized by five state variables: (i) Current age $t$; (ii) net (tangible) wealth $w_{t}$; (iii) the individual's Social Security benefit claiming state $s s_{t}$; (iv) the individual's health status, and (v) the individual's average wage, $a w_{t}{ }^{11}$ For computational simplicity, we assume that decisions are made annually rather than monthly, but we allow for the benefit adjustments due to earnings above the Earnings Test limit to happen semi-annually. This means that although individuals can only decide to claim benefits at the time they turn 62,63 , etc. their Social Security state can be updated every year, depending in their labor earnings, to reflect that their benefits will be adjusted for benefits withheld for periods of six months, or one year. Since the adjustment in benefits becomes effective only after they reach the NRA individuals still receive benefits at the original claiming rate in the period between the time of withholding of benefits until the NRA, consistent with current rules.

The $s s_{t}$ variable can assume up to fourteen mutually exclusive values between 62 and 66: $s s_{t}=0$ (not entitled to benefits), $s s_{t}=62$ (entitled to OASI benefits at the ERA), and $s s_{t}=62.5,63,63 n, 63.5,64,64 n, \ldots, 65.5,66,66 n$ represents the remaining 12 Social Security states corresponding to the level of benefits individuals will receive when they reach the NRA. For individuals who decide to claim after the NRA, $s s_{t}$ can take four additional values, age 67 to 70, since everyone is assumed to claim no later than age 70. We created an additional (implicit state) variable, $s s n_{t}$, which can assume up to five mutually exclusive values: $s s n_{t}=0$ (all benefits

\footnotetext{
11 This translates into a problem with over half a million states in which to solve the model (80 periods, 15 discretized wealth states, 8 discretized average wage states, 3 health states, and 18 Social Security states). We are able to solve this model and simulate it 10,000 times in under 20 minutes in a Dual-Processor Linux Machine with 3.6GHz Xeon Processors using Gauss, and exploiting its capability to link dynamic libraries written in C by the authors and some of their co-authors. These $\mathrm{C}$ libraries perform over $95 \%$ of the computations involved in solving and simulating these models. The code used for these simulations is available upon request, and will eventually be available on the web.
} 
received, i.e. no benefits withheld), $s s n_{t}=1$ (representing an original claim at age 62 of someone who had some benefits withheld; this applies, for example, to individuals with a $s s_{t}$ equal to $62.5,63 n$, or $64 n$ ), $s s n_{t}=2$ (representing an original claim at age 63 for someone who had some benefits withheld), $s s n_{t}=3$ (representing an original claim at age 64 for someone who had some benefits withheld), etc. With this structure we are able to separate, for example, whether someone is a 63 claimer, denoted by $s s_{t}=63$, or is really a 62 claimer who has accumulated one year of withheld benefits, represented here by $s s_{t}=63 n$. These two individuals will receive the same amount of benefits after the NRA, but their benefit would differ before the NRA, as explained in the Appendix, and in additional detail in Benítez-Silva and Heiland (2006a, and 2006b).

In addition to age, wealth, health, Social Security status, Benefit Adjustment status, and current income, the average indexed wage is a key variable in the dynamic model, serving two roles: (1) it acts as a measure of permanent income that serves as a convenient sufficient statistic for capturing serial correlation and predicting the evolution of annual wage earnings; and (2) it is key to accurately model the rules governing payment of the Social Security benefits. An individual's highest 35 years of earnings are averaged and the resulting Average Indexed Earnings (AIE) is denoted as $a w_{t}{ }^{12}$ The PIA is the potential Social Security benefit rate for retiring at the NRA. It is a piece-wise linear, concave function of $a w_{t}$, whose value is denoted by pia $\left(a w_{t}\right)$.

In principle, one needs to keep as state variables the entire past earnings history. To avoid this, we follow Benítez-Silva, Buchinsky, and Rust (2006) and approximate the evolution of average wages in a Markovian fashion, i.e., period $t+1$ average wage, $a w_{t+1}$, is predicted using only age, $t$, current average wage, $a w_{t}$, and current period earnings, $y_{t}$. Within a log-normal regression

\footnotetext{
12 If there is less than 35 years of earnings when the person first becomes eligible for OASI, then the 5 lowest years of earnings are dropped and the remaining wages are averaged. Social Security usually reports the monthly equivalent or AIME.
} 
model, we follow Benítez-Silva, Buchinsky, and Rust (2003), such that the average wages take the form:

$$
\log \left(a w_{t+1}\right)=\gamma_{1}+\gamma_{2} \log \left(y_{t}\right)+\gamma_{3} \log \left(a w_{t}\right)+\gamma_{4} t+\gamma_{5} t^{2}+\varepsilon_{t}
$$

The $R^{2}$ for this type of regression is very high, with an extremely small estimated standard error, resulting from the low variability of the $\left\{a w_{t}\right\}$ sequences. This is a key aspect of the model given the important computational simplification that allows us to accurately model the Social Security rules in our DP model with minimal number of state variables.

We then use the observed sequence of average wages as regressors to estimate the following log-normal regression model of an individual's annual earnings:

$$
\log \left(y_{t+1}\right)=\alpha_{1}+\alpha_{2} \log \left(a w_{t}\right)+\alpha_{3} t+\alpha_{4} t^{2}+\eta_{t}
$$

This equation describes the evolution of earnings for full-time employment. Part-time workers are assumed to earn a pro-rata share of the full-time earnings level (i.e., part-time earnings are $0.8 \cdot 800 / 2000$ of the full-time wage level given in equation (2)). The factor of 0.8 incorporates the assumption that the rate of pay working part-time is $80 \%$ of the full-time rate. Using the history of earnings from the restricted HRS data set we obtained very high $R^{2}$ using this methodology.

The advantage of using $a w_{t}$ instead of the actual Average Indexed Earnings is that $a w_{t}$ becomes a sufficient statistic for the person's earnings history. Thus we need only keep track of $a w_{t}$, and update it recursively using the latest earnings according to (1), rather than having to keep track of the entire earnings history in order to determine the 35 highest earnings years, which the AIE requires.

For the 1943-1954 cohort the NRA is 66 and the PIA is permanently reduced after the NRA by an actuarial reduction factor of $\exp \left(-g_{1}(k-a d j m)\right)$, where $k$ is the number of years prior 
to the NRA but after the ERA that the individual first starts receiving OASI benefits and adjm corrects for periods where no benefits were received due to earnings above the Earnings test limit. Before the NRA, benefits are reduced by an actuarial reduction factor of $\exp \left(-g_{1} k\right)$. In the absence of adjustments to the ARFs, the actuarial reduction rate for the 1943 to 1954 cohort is $g_{1}=.0713$, which results in a reduced benefit of $75 \%$ of the PIA for an individual who first starts receiving OASI benefits at age 62 in the absence of any adjustments of the ARFs. In the policy simulations that increase the NRA to 67 , the reduced benefit at age 62 is $70 \%$ of the PIA.

To increase the incentives to delay retirement, the 1983 Social Security reforms gradually increased the NRA from 65 to 67 and increased the delayed retirement credit (DRC). This is a permanent increase in the PIA by a factor of $\exp \left\{g_{2} l\right\}$, where $l$ denotes the number of years after the NRA that the individual delays receiving OASI benefits. The rate $g_{2}$ is being gradually increased over time. The relevant value for the 1943 to 1954 cohort is $g_{2}=0.0769$, which corresponds to an increase in $8 \%$ in benefits per year of delay after the NRA. The maximum value of $l$ is MRA-NRA, where MRA denotes a "maximum retirement age" (currently 70), beyond which further delays in retirement yield no further increases in PIA. As noted above, it is not optimal to delay applying for OASI benefits beyond the MRA, because due to mortality, further delays generally reduce the present value of OASI benefits the person will collect over their remaining lifetime.

We assume that the individual's utility is given by

$$
u_{t}(c, l, h, a g e)=\frac{c^{\gamma}-1}{\gamma}+\phi(a g e, h, a w) \log (l)-2 h
$$

where $h$ denotes the health status and $\phi($ age, $h, a w)$ is a weight that can be interpreted as the relative disutility of work. We use the same specification for $\phi$ and the disutility from working as in Benítez-Silva, Buchinsky, and Rust (2006). The disutility of work increases with age, and 
is uniformly higher the worse one's health is. If an individual is in good health, the disutility of work increases much more gradually with age compared to the poor health, or disabled health, states. The disutility of work decreases with average wage. We postulate that high wage workers, especially highly educated professionals, have better working conditions than most lower wage blue collar workers, whose jobs are more likely to involve less pleasant, more repetitive, working conditions and a higher level of physical labor. Figure 1 plots the function $\phi$ that we used in the solution and simulations of the life-cycle model.
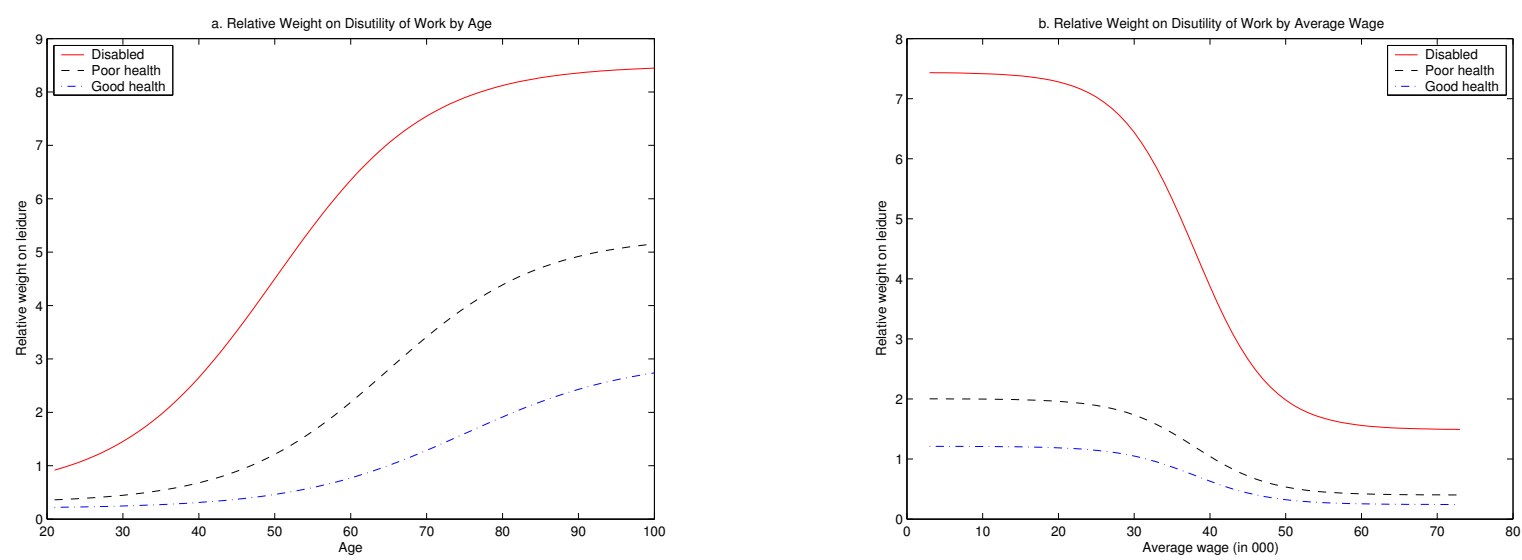

Figure 1: Relative Weight on Leisure as a Function of Age, Health and Average Wage

We assume that there are no time or financial costs involved in applying for OASI benefits.

The parameter $\gamma$ indexes the individual's level of risk aversion. As $\gamma \rightarrow 0$ the utility of consumption approaches $\log (c)$. We use $\gamma=-.37$, which corresponds to a moderate degree of risk aversion, i.e., implied behavior that is slightly more risk averse than that implied by logarithmic preferences.

Let $V_{t}(w, a w, s s, h)$ denote the individual's value function, the expected present discounted value of utility from age $t$ onward for an individual with current wealth $w$, average wage $a w$, in Social Security state $s s$ and health state $h$. We solved the DP problem via numerical computation of the Bellman recursion for $V_{t}$ given by 


$$
\begin{aligned}
& l \in\{.54, .81,1\} \\
& s s d \in A_{t}(s s) \\
& V_{t}(w, a w, s s, c, l, s s d, h)=u_{t}(c, l, h)+\beta\left[1-d_{t}(h)\right] E V_{t+1}(w, a w, s s, c, l, s s d, h), \\
& +d_{t}(h) E B(w, a w, s s, c, l, s s d, h) \text {. }
\end{aligned}
$$

where $A_{t}(s s)$ denotes the set of feasible Social Security choices for a person of age $t$ in Social Security state $s s$ and $d_{t}(h)$ denotes the age and health-specific mortality rate, $B(w)$ is the bequest function, and $E B$ denotes its conditional expectation. We have used the HRS and AHEAD data to estimate age and health-specific death rates, but since there is little data on individuals over 80 years old we make parametric smoothness assumptions on the $d_{t}(h)$ function (basically a logit functional form that is polynomial in $t$ and has dummy variables for the various health states $h$ ) and subject the estimates to the further restriction that for each $t$ the expected hazard over $h$ should equal the unconditional age-specific death rates given in the 1997 edition of the U.S. Decennial life tables. ${ }^{13}$ The function $E V_{t+1}$ denotes the conditional expectation of next period's value function, given the individual's current state $(w, a w, s s, h)$ and decision $(c, l, s s d)$. Specifically, we have

$$
\begin{aligned}
E V_{t+1}(w, a w, s s, c, l, s s d, h)= & \int_{y^{\prime}} \sum_{h^{\prime}=0}^{2} \sum_{s s^{\prime}=0}^{17} V_{t+1}\left(w p_{t}\left(w, a w, y^{\prime}, s s, s s d\right), a w p_{t}\left(a w, y^{\prime}\right), s s^{\prime}\right) \\
& \times f_{t}\left(y^{\prime} \mid a w\right) k_{t}\left(h^{\prime} \mid h\right) g_{t}\left(s s^{\prime} \mid a w, w, s s, s s d\right) d y^{\prime}
\end{aligned}
$$

where $a w p_{t}(a w, y)$ is the Markovian updating rule that approximates Social Security's exact formula for updating an individual's average wage, and $w p_{t}$ summarizes the law of motion for

\footnotetext{
13 De Nardi, French, and Jones (2006) find that more sophisticated mortality characterizations do not seem to significantly improve the fit of a related dynamic structural model which focuses on post-retirement saving behavior.
} 
next period's wealth, that is,

$$
w p_{t}(w, a w, y, s s, s s d)=R\left[w+s s b_{t}\left(a w, y^{\prime}, s s, s s d\right)+y^{\prime}-\tau\left(y^{\prime}, w\right)-c\right]
$$

where $R$ is the return on saving, and $\tau(y, w)$ is the tax function, which includes income taxes such as Federal income taxes and Social Security taxes and potentially other types of state/local income and property/wealth taxes. The $a w p_{t}$ function, derived from (1), is given by

$$
a w p_{t}(a w, y)=\exp \left\{\gamma_{1}+\gamma_{2} \log (y)+\gamma_{3} \log (a w)+\gamma_{4} t+\gamma_{5} t^{2}+\sigma^{2} / 2\right\}
$$

where $\sigma$ is the estimated standard error in the regression (1). Note there is a potential "Jensen's inequality" problem here due to the fact that we have substituted the conditional expectation of $w_{t+1}$ into the next period value function $V_{t+1}$ over $w_{t+1}$ and $a w_{t+1}$ jointly. However, as noted above, the $R^{2}$ for the regression of $a w_{t+1}$ on $a w_{t}$ is virtually 1 with an extremely small estimated standard error $\hat{\sigma}$. In this case there is virtually no error resulting from substituting what is an essentially deterministic mapping determining $a w_{t+1}$ from $w_{t+1}$ and $a w_{t}$.

Above, $f_{t}(y \mid a w)$ is a log-normal distribution of current earnings, given current age $t$ and average wealth $a w$, that is implied by (2) under the additional assumption of normality of errors $\eta_{t}$. The discrete conditional probability distributions $g_{t}\left(s s^{\prime} \mid a w, w, s s, s s d\right)$ and $k_{t}\left(h^{\prime} \mid h\right)$ reflect the transition probabilities in the Social Security and health states, respectively.

Finally, to account for the Social Security reform expectations, we introduce in the optimization process the possibility that with a probability of $4.825 \%$, the agents faced a modified equation (4), with a modified equation (6) and modified law of motion for wealth, which embeds a permanent drop in benefits of $5.75 \%$. 


\section{Simulation Results and Policy Experiments}

Table 3 reports the results for three different models of Social Security, assuming a NRA of 66. Model 1 treats the earnings test as a pure tax on earnings above the corresponding ET limit, which is how it may be perceived by a proportion of the general public given difficulty in understanding complex adjustment factors for working beyond take-up (Benítez-Silva and Heiland, 2006a and 2006b), and how a majority of researchers have modeled these incentives. Using this framework, our model of optimal behavior predicts that only about $35 \%$ of claimers would take up at age 62 , with a much smaller peak at 65 at roughly $18 \%$, with a bulk of the remaining beneficiaries claiming at the ages in between. Benefits, given this behavior, increase slightly with age at all points so that there are economic incentives for delaying take-up.

With the implementation of the proper Earnings Test incentives, which allow for the modification of the actuarial reduction factor through work after take-up with earnings above the ET limit, Model 2 shows a trend towards earlier claiming of benefits. This moves us closer to the actual take-up rates with a jump from only $35 \%$ claiming at 62 in Model 1 to over $48 \%$ in Model 2. The actual current take-up rate is around 56.6\% (SSA Statistical Supplement, 2006). There continues to be a second smaller peak at age 65 with $23 \%$ of the sample holding out for the unpenalized NRA benefit. Only $4 \%$ of the sample hold off until after 65 for taking up when the penalty for working after take-up is reduced compared to $11 \%$ in Model 1.

While the biggest jump toward actual behavior comes from adding to the model the possibility to affect the adjustment factors, introducing, on top of Model 2, Social Security benefit uncertainty (Model 3) comes very close to predicting actual behavior. The predicted take-up in this framework where people perceive a potential risk to delaying take-up goes up to $59 \%$, compared to the $57 \%$ actual take up rates at this age. The peak at age 65 falls to $21 \%$ compared to 
predictions from Model 2 (which predicts $23 \%$ take-up), and this again is closer to the actual rate of $19 \%$. More people are willing to take lower benefits earlier, knowing they can move closer to the full benefit with the ARF adjustments, and preferring the actuarial reduction with certainty over future uncertain cuts.

The comparison between Models 2 and 3 provides a sense of the effects of reducing uncertainty over reforms. We can see that Model 2 predicts more full-time work, especially at age 62 , but also in later ages, due to the strong connection between claiming behavior and labor supply These results are broadly consistent with the findings of Bütler's (1999), who indicates that uncertainty considerations are important, and that governments can reduce the amount of uncertainty agents have to deal with, resulting in welfare improving allocations, by providing better information regarding the timing and the type of reforms in store.

One of the advantages of dynamic models is that it allows us to perform a welfare analysis. We have computed compensating variations, which capture the willingness to pay, or in this case the need to be compensated, for having to face the uncertainty over Social Security reforms. We find that given that the uncertainties are never realized, the differences in welfare are very small, and affect only a small proportion of individuals. Only about $5 \%$ of individuals in our simulations see a drop in their welfare, and among those the drops in welfare account for less than $1.5 \%$ of their average wealth in the simulations. This suggests that eventhough the changes in behavior resulting from this source of uncertainty are clearly non trivial, many of the individuals forced to claim earlier were originally close to indifferent with respect to claiming at other ages.

The last column in the three panels of Table 3 shows the benefit levels predicted by the model. Notice how close they are to the actual benefits received by Older Americans, which we reported in Table 2. This comes to show how accurate our model is in matching qualitatively, 
and quantitatively, even in dollar terms, actual data. Given that we are using a NRA of 66, and therefore individuals face the Earnings Test between age 65 and 66, the relationship between benefits levels at different ages is closer to that present in the period before the elimination of the ET for those above the NRA. This translates in the prediction that later claimers obtain higher benefits.

In this paper we focus on claiming behavior and labor supply, but the model also simulates the evolution of wealth, consumption, and wages over the life cycle. As shown in Benítez-Silva, Buchinksy, and Rust (2006), in a closely related model, the predictions of the model are consistent with the HRS data.

Table 4 simulates behavioral responses to increasing the NRA to 67 . We resolve and resimulate the same three models with this modification. Under the policy of an earnings test as a pure tax, increasing the normal age to 67 yields the implicit and desired effects of the policydelaying take-up, and likely retirement. With the original NRA of 66, more than half of the beneficiaries claim by age 63 . When the NRA increases about half of the beneficiaries are claiming at ages 65 and 66. From the last column we see they have to work more to earn the same benefits. This is a pure benefit cut and the responses that are predicted are not what we observe in the data.

Adding in the appropriate ET rules leads us to conclude that with a more realistic set of incentives, the predictions move significantly closer to the real outcomes. With the higher NRA, the take up rate at 62 increases holding the rest of the features of Model 2 constant. There is no longer a peak at 65 nor is there one at 67 . The next peak is at age 66 . It is not until we move to Model 3, where we allow for uncertainties over future benefit guarantees, that do we get that second peak back at age 65, as in the actual data. Again, increasing the NRA only moves people 
toward earlier claiming of retirement benefits in these last two models and we see little action in terms of desired behavioral consequences.

These findings support the sound economic intuition that any policy that does not affect the ratio between the benefits received at different ages (for example, any further increases in the NRA, which are nothing but benefits cuts affecting all claiming ages equally) should not be expected to have much impact on claiming behavior, and therefore relatively little is to be expected in terms of labor supply responses, except maybe some increases in order to compensate for the loss of benefits.

It is clear from these results that only a model that accounts for the appropriate incentive scheme and that is able to match the claiming behavior of individuals, can be reliably used as a policy instrument. The predictions of a simplistic and misspecified model are erroneous and misleading. Unfortunately, many previous and current policy makers seem to gain their intuitions from such a faulty framework, with the consequence of defending changes to the system which have few real meaningful effects.

\section{Conclusions}

We use a dynamic life cycle framework to model the majority of the complexities of the Old Age Social Security program, as well as expectations of future benefit cuts to predict benefit claiming behavior. The attention to detail in terms of the incentives, and the modeling of the very plausible expectation of future cuts, pays off in terms of predictive power in terms of claiming behavior of Older Americans. The latter have been extremely elusive in previous models using recent data. We then use the expanded model to show that the increases in NRA, which are currently being 
implemented, and the possible further increases being debated, do very little to change a properly modeled incentive structure, suggesting the lack of efficacy of pure benefit cuts to promote lasting changes in behavior.

On the other hand, expectations about future benefits seem to have a big impact, and given the reality of the Social Security burden, there is little policy can do to alter those expectations. There have to be cuts in some way. Mandating a set of cuts, with some serious commitment to fix the program for more than a couple of decades, so that there are no expectations of benefits cuts again, should delay take-up and alleviate, at least in part, the financial crisis. The necessary cuts for this plan to succeed would impose undue burden on a generation that would result in severe welfare losses. The challenge can be understood in the context of the work of Auerback and Hasset (2006), who discuss sticky policies. Unfortunately when it comes to Social Security, policies are not sticky enough so that there is little confidence in future benefit amounts among planners.

From a policy perspective our results suggest a complex environment where intuitions based on simple models can lead to large miscalculations. No policy reform will be simple, and even simplifications of the system, like the elimination of the Earnings Test, would not necessarily solve too many problems, as shown in Benítez-Silva and Heiland (2006b). ${ }^{14}$

\footnotetext{
${ }^{14}$ French (2005), using his estimates from a dynamic structural model, performs the experiment of removing the earnings test for those between age 65 and 70 . He finds large effects in terms of the hours worked after age 65, and also in terms of the number of years in the labor force, even if the average hours worked by workers are largely unchanged. Although these are results in a partial equilibrium setting, they indicate that a possible removal of the Earnings Test for those between the ERA and the NRA would have significant effects on the labor supply of older Americans. Gruber and Orszag (2000), using the CPS and taking a more descriptive approach, find little evidence of the effects of the Earnings Test on the labor supply of men, but some evidence of effects on benefit claiming behavior. Song (2004) using the SIPP finds that the removal of the ET leads to uneven effects over the earnings distribution, with large effects on the earnings of high earners. The author also finds an increase in claiming for the 65 to 69 age group. More recently, Song and Manchester (2006) using SSA's Continuous Work History Sample reach similar conclusions. Gustman and Steinmeier (2004) find that the removal of the Earnings Test worsens (especially in the short run) the cash flow problems of Social Security due to greater incidence of early benefit claiming. Their analysis does not, however, account for potential administrative cost savings.
} 
The increase in the early retirement age would have a mechanical effect, but is likely to be highly regressive. It is possible that in order to obtain financial relief beyond that of benefits cuts, through labor supply increases, it is necessary to device an actuarially unfair incentive structure in which late claiming is better compensated. The later would be made hoping that the actual labor supply responses, and the resulting tax revenues, compensate for the cost of such a policy, which although regressive might be less so than just increasing the ERA. 


\section{Appendix: Social Security Incentives for Early Retirement}

Individuals who claim benefits before the NRA but continue to work or reenter the labor force can reduce the early retirement penalty by suspending benefit payments. ${ }^{15}$ The Actuarial Reduction Factor (or early retirement reduction factor), in turn, will be increased proportionally to the number of months without benefits, which will increase benefits permanently after the individual reaches the NRA. ${ }^{16}$ This adjustment of the ARF allows those who become beneficiaries before the NRA to partially or completely reverse the financial consequences of their decision, averting being locked-in at the reduced rate. In the sequel of this section the exact details of these incentives are presented.

\section{Benefit Calculation}

Individuals aged 62 or older who had earned income that was subject to the Social Security payroll tax for at least 10 years since 1951 are eligible for retirement benefits under the Old Age benefits program. Earnings are subject to the tax up to an income maximum that is updated annually according to increases in the average wage. ${ }^{17}$ To determine the monthly benefit amount (MBA), the Social Security Administration calculates the Primary Insurance Amount (PIA) of a worker as a concave piece-wise linear function of the worker's average earnings subject to Social Security taxes taken over her 35 years of highest earnings. If the benefits are claimed at the NRA (66 for those born between 1943 and 1954, and currently at 65 and 8 months), the MBA equals the PIA. If an individual decides to begin receiving benefits before the NRA and exits the labor force or stays below the earnings limit, her MBA is reduced by up to 25\%, assuming a NRA of 66. Under the current regulation of the OA program, the monthly benefit amount received upon first claiming benefits depends on the age (month) of initiation of Social Security benefits, in the following way,

$M B A_{t}=\left\{\begin{array}{c}\left(0.75+0.05 * \frac{1}{12} *(\text { Months not claimed in the period prior to } 3 \text { years before NRA })\right) * P I A \\ \text { if claimed more than } 3 \text { years before NRA; } \\ \left(0.80+0.20 * \frac{1}{36} *(\text { Months not claimed in } 3 \text { years before NRA })\right) * P I A \\ \text { if claimed within the } 3 \text { years before NRA. }\end{array}\right.$

where $M B A_{t}$ represents the monthly benefit amount before the NRA (see SSA-S 2005, p.18). Assuming that the individual continues to receive benefits, her $M B A_{t}$ is permanently reduced. The Actuarial Reduction Factor (ARF) underlying this calculation is a permanent reduction of

\footnotetext{
${ }^{15}$ In this paper, we are not considering spousal benefits and joint decision making in the household. The complexities introduced by those considerations are out of the scope of this analysis. See Gustman and Steinmeier (1991), Coile, Diamond, Gruber, and Jousten (2002), and Votruba (2003) for a discussion. By ignoring spousal benefits we are not taking into account the fact that approximately $5.96 \%$ of the individuals who receive some type of Old Age, Survivors, or Disability Insurance (OASDI) benefits receive them as spouses of entitled retirees. This percentage comes from the Public-Use Microdata File provided by the Social Security Administration and refers to a $1 \%$ random sample of all beneficiaries as of December of 2001.

16 Given a NRA of 66, which will be the prevailing one for the cohort born between 1943 and 1954, the Actuarial Reduction Factor is a number between 0.75 and 1 depending on when the individual claims benefits, and how many months he or she earns above the Earnings Test after claiming benefits.

17 Six percent of the 153 million workers with Social Security taxable earnings in 2002 had earnings at or above the maximum amount.
} 
benefits by $5 / 9$ of 1 percent per month for each month in which benefits are received in the three years immediately prior to the NRA. The reduction of benefits is $5 / 12$ of 1 percent for every month before that. Thus, the maximum actuarial reduction will reach 30 percent as the NRA increases to 67 over the next few years (see SSA-S 2005, p.18). ${ }^{18}$

\section{Actuarial Reduction Factor}

One less-emphasized feature of the process of benefit reduction due to early retirement is the possibility to reduce the penalty even after initiating the receipt of benefits. The specifics of this adjustment to the Actuarial Reduction Factor are documented in the Social Security Handbook (SSA-H, §724. Basic reduction formulas, §728. Adjustment of reduction factor at FRA) and in the internal operating manual used by Social Security field employees when processing claims for Social Security benefits (SSA-M, RS00615. Computation of Monthly Benefits Amounts) but may not be well-understood by the retirees. ${ }^{19}$ To illustrate this feature of the system, suppose the NRA is 66 years, and an individual claims benefits at age 62 and $n$ months, where $n<<48$, receives checks for $x$ months where $(n+x<<48)$, and suspends receiving checks after that until she turns 66 (after which she retires for good). In this case she receives $x$ checks of

$$
M B A_{t}= \begin{cases}\left(0.75+0.05 * \frac{1}{12} * n\right) * P I A & \text { if claimed more than } 3 \text { years before NRA; } \\ \left(0.80+0.20 * \frac{1}{36} * n\right) * P I A & \text { if claimed within the } 3 \text { years before NRA }\end{cases}
$$

After turning 66, her $M B A$ will be permanently increased to

$$
M B A_{t}=\left[0.75+\left(0.20 * \frac{1}{36} * n\right)+\left(0.20 * \frac{1}{36} *(36-n-x)\right)+0.05\right] * \text { PIA }
$$

It is important to note that the adjustment of the ARF is automatic and becomes effective only after reaching the NRA.

\section{Earnings Test}

The Earnings Test limit defines the maximum amount of income from work that a beneficiary who claims benefits before the NRA under OASI may earn while still receiving the "full" $M B A .{ }^{20}$

\footnotetext{
18 The reductions in benefits for early claimers are designed to be approximately actuarially fair for the average individual. During the post-NRA period additional adjustments exist: Workers claiming benefits after the NRA earn the delayed retirement credit (DRC). For those born in 1943 or later it is $2 / 3$ of 1 percent for each month up to age 70 which is considered actuarially fair. For those born before 1943 it ranges from 11/24 to 5/8 of 1 percent per month, depending on their birth year.

19 The Social Security Administration does not use the term Actuarial Reduction Factor in their publications, but a number of the people we have talked to within the administration do use this terminology. In publications the related concept of "Reduction Factor(s)" (RF) which is simply the number of months in which benefits were received before the NRA is used. The RF maps into a "Fraction" that ranges between 0.75 and 1 (for an ERA of 62 and an NRA of 66). The latter corresponds to what we refer to as ARF. The ARF ("Fraction") is adjusted upwards at the NRA according to the number of months before the NRA in which benefits were withheld.

20 Some sources of income do not count under the Earnings Test. For details see SSA-H §1812. Notice that retirement contributions by the employer do not count towards the limit, but additional contributions by the employee even if they are through a payroll deduction are counted. This means that individuals earning above the limit cannot just increase their retirement savings to avoid being subject to the limit. We thank Barbara Lingg and Christine Vance from the Social Security Administration for clarifying this point, which is rarely discussed in any publication.
} 
Earnings above the limit are taxed at a rate of 50 percent for beneficiaries between age 62 and the January of the year in which they reach the NRA, and 33 percent from January of that year until the month they reach the NRA (SSA-S 2005, p.19; SSA-S 2005, Table 2.A18). For the latter period, the earnings limit is higher, $\$ 31,800$, compared with $\$ 12,000$ for the earlier period as of 2005 (SSA-S 2005, Table 2.A29). Starting in 2000, the Earnings Test was eliminated for individuals over the NRA.

Individuals who continue or reenter employment after claiming Social Security benefits before the NRA, and whose earning power or hours constraints are such that their income from work is around or below the earnings limit, are mailed their full monthly check from Social Security and are locked-in at the reduced benefit rate permanently. Those with earnings above the limit will not receive checks from Social Security for some months and thereby adjust their ARF. ${ }^{21}$ Individuals have the option of informing Social Security to suspend the monthly benefit payment at any time if they believe they will be making earnings high enough above the Earnings Test. However, during the first year after claiming benefits, the Social Security Administration performs a monthly test to determine whether the person should receive the monthly check. As a result an early claimer who is not working or earns below the limit in the months after claiming ("grace year") will receive all monthly benefits even if earnings for that calendar year exceed the Earnings Test limit due to high earnings before claiming. ${ }^{22}$ After the first year, the test is typically yearly and it depends on the expected earnings of the individual. Given the scarce documentation of the functioning of the ARF, having earned above the earnings limit, and thus receiving fewer checks, may be a common way for beneficiaries to learn about the possibility of undoing the early retirement penalty. ${ }^{23}$

\footnotetext{
${ }^{21}$ A beneficiary may receive a partial monthly benefit at the end of the tax year if there are excess earnings that do not completely offset the monthly benefit amount (see SSA-H, §1806).

22 Social Security claim specialists emphasized to us that during the first year after claiming they do what is most advantageous to the claimer, the monthly or the yearly test, if they have enough information. However, they failed to clarify what that means. Some of them said the number of checks individuals receive is maximized, but we were unable to find documentation of such practices. In any case, the internal operating instructions used by Social Security field employees when processing claims for Social Security benefits state that the monthly earnings test only applies for the calendar year when benefits are initiated unless the type of benefit changes (see SSA-M, RS02501.030).

${ }^{23}$ See Benítez-Silva and Heiland (2006b) for a numeric example of the streams of income resulting from these incentives.
} 
Table 1: Social Security Claiming Behavior, 1999-2005. Proportions by age of first receipt.

\begin{tabular}{lccccccc}
\hline Age/Year & $\mathbf{1 9 9 9}$ & $\mathbf{2 0 0 0}$ & $\mathbf{2 0 0 1}$ & $\mathbf{2 0 0 2}$ & $\mathbf{2 0 0 3}$ & $\mathbf{2 0 0 4}$ & $\mathbf{2 0 0 5}$ \\
\hline Age 62 & 0.585814 & 0.517198 & 0.553939 & 0.560256 & 0.569939 & 0.575377 & 0.566377 \\
Age 63 & 0.079887 & 0.067144 & 0.077954 & 0.077716 & 0.078255 & 0.081044 & 0.083014 \\
Age 64 & 0.107773 & 0.104554 & 0.134435 & 0.148463 & 0.127389 & 0.109411 & 0.099255 \\
Age 65 & 0.155732 & 0.195975 & 0.178526 & 0.172416 & 0.178465 & 0.186224 & 0.197471 \\
Age 66 & 0.019467 & 0.039229 & 0.013024 & 0.009695 & 0.010518 & 0.012259 & 0.014628 \\
Age 67-69 & 0.029166 & 0.055034 & 0.019949 & 0.015288 & 0.016098 & 0.017789 & 0.018782 \\
Age 70+ & 0.022161 & 0.020865 & 0.022173 & 0.016166 & 0.019366 & 0.017896 & 0.020474 \\
\hline Total & $1,484,600$ & $1,758,900$ & $1,574,000$ & $1,595,530$ & $1,593,271$ & $1,680,339$ & $1,793,537$ \\
\hline
\end{tabular}

Table 2: Social Security beneficiaries' monthly benefits by age, 1999-2005. In \$ of 2005.

\begin{tabular}{lccccccc}
\hline Age/Year & $\mathbf{1 9 9 9}$ & $\mathbf{2 0 0 0}$ & $\mathbf{2 0 0 1}$ & $\mathbf{2 0 0 2}$ & $\mathbf{2 0 0 3}$ & $\mathbf{2 0 0 4}$ & $\mathbf{2 0 0 5}$ \\
\hline Age 62 & 855.64 & 864.56 & 884.42 & 892.58 & 900.40 & 888.31 & 881.90 \\
Age 63 & 928.79 & 960.51 & 973.08 & $1,002.77$ & $1,006.43$ & 996.66 & 986.90 \\
Age 64 & 987.87 & $1,020.39$ & $1,072.88$ & $1,119.80$ & $1,119.68$ & $1,102.01$ & $1,089.80$ \\
Age 65 & $1,100.29$ & $1,184.50$ & $1,176.10$ & $1,239.22$ & $1,257.03$ & $1,270.85$ & $1,298.30$ \\
Age 66 & $1,093.73$ & $1,247.67$ & 939.56 & 881.73 & 919.08 & 981.26 & $1,052.20$ \\
Age 67 & $1,128.66$ & $1,285.78$ & 911.44 & 873.48 & 877.89 & 933.59 & $1,010.40$ \\
\hline
\end{tabular}


Table 3: Simulation Results: 10,000 Simulations of the Dynamic Model

\begin{tabular}{|c|c|c|c|c|c|c|}
\hline Ages & Survivors & Full-Time $^{a}$ & Part-Time $^{a}$ & No Work ${ }^{a}$ & Claimers $^{b}$ & Benefits in \$ \\
\hline & \multicolumn{6}{|c|}{ Model 1: Earnings Test as a Tax } \\
\hline Age 60 & 8,234 & $5,749(69.8 \%)$ & $163(5.7 \%)$ & $2,322(28.8 \%)$ & - & - \\
\hline Age 61 & 8,078 & $5,635(69.7 \%)$ & $213(2.6 \%)$ & $2,230(27.6 \%)$ & - & - \\
\hline Age 62 & 7,951 & $4,714(59.2 \%)$ & $2(0.02 \%)$ & $3,235(40.6 \%)$ & $2,672(34.9 \%)$ & 1,042 \\
\hline Age 63 & 7,762 & $2,013(25.9 \%)$ & $856(11.0 \%)$ & $4,893(63.0 \%)$ & $1,331(17.4 \%)$ & 1,151 \\
\hline Age 64 & 7,586 & $495(6.5 \%)$ & $2,008(26.4 \%)$ & $5,083(67.0 \%)$ & $1,048(13.7 \%)$ & 1,272 \\
\hline Age 65 & 7,420 & $113(1.5 \%)$ & $2,731(36.8 \%)$ & $4,576(61.6 \%)$ & $1,362(17.8 \%)$ & 1,391 \\
\hline \multirow[t]{2}{*}{ Age 66} & 7,239 & $414(5.7 \%)$ & $3,484(48.1 \%)$ & $3,341(46.1 \%)$ & $847(11.0 \%)$ & 1,500 \\
\hline & \multicolumn{6}{|c|}{ Model 2: Earnings Test with ARF Adjustments } \\
\hline Age 60 & 8,234 & $5,749(69.8 \%)$ & $154(1.8 \%)$ & $2,331(28.3 \%)$ & - & - \\
\hline Age 61 & 8,078 & $5,636(69.7 \%)$ & $214(2.6 \%)$ & $2,228(27.5 \%)$ & - & - \\
\hline Age 62 & 7,951 & $4,058(51.0 \%)$ & 0 & $3,893(49.0 \%)$ & $3,741(48.3 \%)$ & 981 \\
\hline Age 63 & 7,762 & $1,657(21.3 \%)$ & $1,387(17.8 \%)$ & $4,718(60.7 \%)$ & $1,073(13.8 \%)$ & 1,155 \\
\hline Age 64 & 7,586 & $434(5.7 \%)$ & $2,413(31.8 \%)$ & $4,739(62.5 \%)$ & $815(10.5 \%)$ & 1,277 \\
\hline Age 65 & 7,420 & $175(2.4 \%)$ & $3,139(42.3 \%)$ & $4,106(55.3 \%)$ & $1,808(23.3 \%)$ & 1,390 \\
\hline Age 66 & 7,239 & $553(7.6 \%)$ & $4,179(57.7 \%)$ & $2,507(34.6 \%)$ & $306(4.1 \%)$ & 1,480 \\
\hline
\end{tabular}

\begin{tabular}{ccccccc}
\hline \multicolumn{7}{c}{ Model 3: ET with ARF Adjustments and Social Security Reform Uncertainty } \\
Age 60 & 8,234 & $5,768(70.05 \%)$ & $118(1.43 \%)$ & $2,348(28.5 \%)$ & - & - \\
Age 61 & 8,078 & $5,636(69.8 \%)$ & $177(2.2 \%)$ & $2,265(28.04 \%)$ & - & - \\
Age 62 & 7,951 & $3,377(42.5 \%)$ & $0(0.00 \%)$ & $4,574(57.5 \%)$ & $4,603(59.08 \%)$ & 997 \\
Age 63 & 7,762 & $1,540(19.9 \%)$ & $2,000(25.8 \%)$ & $4,222(54.4 \%)$ & $813(10.4 \%)$ & 1,180 \\
Age 64 & 7,586 & $394(5.2 \%)$ & $2,802(36.93 \%)$ & $4,390(57.9 \%)$ & $689(8.8 \%)$ & 1,275 \\
Age 65 & 7,420 & $181(2.4 \%)$ & $3,511(47.3 \%)$ & $3,728(50.2 \%)$ & $1,659(21.3 \%)$ & 1,390 \\
Age 66 & 7,239 & $594(8.2 \%)$ & $4,351(60.1 \%)$ & $2,294(31.2 \%)$ & $27(0.4 \%)$ & 1,514 \\
\hline
\end{tabular}

Notes: ${ }^{a}$ In numbers, and as percentage of survivors. ${ }^{b}$ Number of First Claimers at that age, and as percentage of the total who ever claimed. 


\section{Table 4: Policy Experiment: NRA is changed to 67. 10,000 Simulations of the Dynamic Model}

\begin{tabular}{|c|c|c|c|c|c|c|}
\hline Ages & Survivors & Full-Time $^{a}$ & Part-Time $^{a}$ & No Work ${ }^{a}$ & Claimers $^{b}$ & Benefits in \$ \\
\hline & \multicolumn{6}{|c|}{ Model 1: Earnings Test as a Tax, and NRA $=67$} \\
\hline Age 60 & 8,234 & $5,771(70.1 \%)$ & $117(1.4 \%)$ & $2,346(28.5 \%)$ & - & - \\
\hline Age 61 & 8,078 & $5,640(69.8 \%)$ & $166(2.1 \%)$ & $2,272(28.1 \%)$ & - & - \\
\hline Age 62 & 7,951 & $5,530(69.5 \%)$ & 0 & $2,423(30.5 \%)$ & $1,872(24.8 \%)$ & 989 \\
\hline Age 63 & 7,762 & $4,237(54.6 \%)$ & $194(2.5 \%)$ & $3,331(42.9 \%)$ & $446(5.9 \%)$ & 1,110 \\
\hline Age 64 & 7,586 & $1,744(22.9 \%)$ & $514(6.7 \%)$ & $5,328(70.2 \%)$ & $1,040(13.78 \%)$ & 1,212 \\
\hline Age 65 & 7,420 & $1,124(15.1 \%)$ & 0 & $6,298(84.8 \%)$ & $1,884(24.9 \%)$ & 1,234 \\
\hline Age 66 & 7,239 & $848(11.7 \%)$ & 0 & $6,393(88.3 \%)$ & $1,862(24.6 \%)$ & 1,392 \\
\hline \multirow{2}{*}{ Age 67} & 7,041 & $1,078(15.3 \%)$ & 0 & $5,968(84.7 \%)$ & $412(5.46 \%)$ & 1,457 \\
\hline & \multicolumn{6}{|c|}{ Model 2: Earnings Test with ARF Adjustments, and NRA=67 } \\
\hline Age 60 & 8,234 & $5,773(70.1 \%)$ & $123(1.5 \%)$ & $2,338(28.4 \%)$ & - & - \\
\hline Age 61 & 8,078 & $5,636(69.7 \%)$ & $173(2.1 \%)$ & $2,269(28.1 \%)$ & - & - \\
\hline Age 62 & 7,951 & $4,150(52.1 \%)$ & $3(0.03 \%)$ & $3,798(47.8 \%)$ & $4,016(51.96 \%)$ & 886 \\
\hline Age 63 & 7,762 & $2,173(27.99 \%)$ & $1,409(18.1 \%)$ & $4,180(53.85 \%)$ & $996(12.88 \%)$ & 1,049 \\
\hline Age 64 & 7,586 & $839(11.1 \%)$ & $2,400(31.6 \%)$ & $4,347(57.3 \%)$ & $605(7.8 \%)$ & 1,182 \\
\hline Age 65 & 7,420 & $309(4.16 \%)$ & $3,024(40.7 \%)$ & $4,087(55.1 \%)$ & $738(9.55 \%)$ & 1,259 \\
\hline Age 66 & 7,239 & $158(2.2 \%)$ & $3,670(50.69 \%)$ & $3,411(47.1 \%)$ & $1,302(16.84 \%)$ & 1,397 \\
\hline Age 67 & 7,041 & $466(6.6 \%)$ & $4,314(61.3 \%)$ & $2,261(32.1 \%)$ & $71(0.91 \%)$ & 1,516 \\
\hline
\end{tabular}

Model 3: ET with ARF Adjustments, Social Security Reform Uncertainty, and NRA=67

\begin{tabular}{ccccccc} 
Age 60 & 8,234 & $5,765(70.01 \%)$ & $118(1.43 \%)$ & $2,347(28.5 \%)$ & - & - \\
Age 61 & 8,078 & $5,634(69.75 \%)$ & $177(2.2 \%)$ & $2,267(28.06 \%)$ & - & - \\
Age 62 & 7,951 & $3,371(42.4 \%)$ & $0(0.00 \%)$ & $4,578(57.57 \%)$ & $5,084(65.16 \%)$ & 1,060 \\
Age 63 & 7,762 & $2,016(25.97 \%)$ & $2,000(25.8 \%)$ & $3,597(46.3 \%)$ & $714(9.15 \%)$ & 1,073 \\
Age 64 & 7,586 & $769(10.1 \%)$ & $2,802(36.93 \%)$ & $3,883(51.1 \%)$ & $512(6.56 \%)$ & 1,191 \\
Age 65 & 7,420 & $316(4.2 \%)$ & $3,511(47.3 \%)$ & $3,552(47.9 \%)$ & $927(11.9 \%)$ & 1,281 \\
Age 66 & 7,239 & $158(2.2 \%)$ & $4,392(60.6 \%)$ & $2,736(37.8 \%)$ & $561(7.2 \%)$ & 1,398 \\
Age 67 & 7,041 & $499(7.1 \%)$ & $4,392(60.6 \%)$ & $2,217(31.5 \%)$ & $4(0.05 \%)$ & 1,523 \\
\hline
\end{tabular}

Notes: ${ }^{a}$ In numbers, and as percentage of survivors. ${ }^{b}$ Number of First Claimers at that age, and as percentage of the total who ever claimed. 


\section{References}

Auerbach, A., and K. Hassett (2006): "Optimal long-run fiscal policy: Constraints, preferences and the resolution of Uncertainty," Journal of Economic Dynamics and Control, 5 1-22.

Baker, M., and D. Benjamin (1999): "How do retirement tests affect the labour supply of older men?" Journal of Public Economics, 71 27-51.

Benítez-Silva, H., and F. Heiland (2006a): "Early Claiming of Social Security Benefits and Labor Supply Behavior of Older Americans," forthcoming in Applied Economics.

Benítez-Silva, H., and F. Heiland (2006b): “The Social Security Earnings Test Revisited: Information, Distortions, and Costs," manuscript, SUNY-Stony Brook.

Benítez-Silva, H., M. Buchinsky, and J. Rust (2003): "Dynamic Structural Models of Retirement and Disability," manuscript, SUNY-Stony Brook, UCLA, and University of Maryland.

Benítez-Silva, H., M. Buchinsky, and J. Rust (2006): "Induced Entry Effects of a \$1 for \$2 Offset in SSDI Benefits," manuscript, SUNY-Stony Brook, UCLA, and University of Maryland.

Blau, D. (2004): "Retirement and Consumption in a Life Cycle Model," manuscript, University of North Carolina at Chapel Hill.

Burtless, G., and R. A. Moffitt (1985): "The Joint Choice of Retirement Age and PostRetirement Hours of Work," Journal of Labor Economics, 3 209-236.

Bütler, M. (1999): “Anticipation effects of looming public pension-reforms." CarnegieRochester Conference Series on Public Policy, 50 119-159.

Coile, C., P. Diamond, J. Gruber, and A. Jousten (2002): "Delays in Claiming Social Security Benefits," Journal of Public Economics, 84-3 357-385

De Nardi, Mariacristina, E. French, and J.B. Jones (2006): "Differential Mortality, Uncertain Medical Expenses, and the Saving of Elderly Singles," manuscript.

French, E. (2005): “The Effects of Health, Wealth, an Wages on Labour Supply and Retirement Behaviour," Review of Economic Studies, 72 395-427.

Friedberg, L. (1998): “The Social Security Earnings Test and Labor Supply of Older Men,” in Tax Policy and The Economy, Vol. 12. MIT Press.

Friedberg, L. (2000): "The Labor Supply Effects of the Social Security Earnings Test," Review of Economics and Statistics, 82 48-63.

Gruber, J., and P. Orszag (1999): "What To Do About the Social Security Earnings Test?" Center for Retirement Research Brief July 1999 No. 1.

Gruber, J., and P. Orszag (2000): “Does the Social Security Earnings Test Affect Labor Supply and Benefits Receipt?" CRR Working Paper No. 2000-07. 
Gustman, A. L., and T. L. Steinmeier (1985): "Social Security Reform and Labor Supply," NBER Working Paper No. 1212.

Gustman, A.L. and T.L. Steinmeier (2003): "Retirement Effects of Social Security Reform," manuscript, Conference of the Retirement Research Consortium.

Gustman, A.L. and T.L. Steinmeier (2002a): “The New Social Security Commission Personal Accounts: Where is the Investment Principal," NBER Working paper No 9045.

Gustman, A. L., and T. L. Steinmeier (2002b): "The Social Security Early Retirement Age in a Structural Model of Retirement and Wealth,” NBER Working Paper No. 9183.

Gustman, A. L., and T. L. Steinmeier (2004): "The Social Security Retirement Earnings Test, Retirement and Benefit Claiming," Michigan Retirement Research Center No. 2004-090.

Honig, M., and C. Reimers (1989): "Is It Worth Eliminating the Retirement Test?" American Economic Review, 79 103-107.

Judd, K.L. (1998): Numerical Methods in Economics, The MIT Press.

Leonesio, M. V. (1990): "Effects of the Social Security Earnings Test on the Labor Market Activity of Older Americans: A Review of the Evidence," Social Security Bulletin, 53 2-21.

Magnac, T. and D. Thesmar (2002): "Identifying Dynamic Discrete Decision Processes," Econometrica, 70-2 801-816.

Mastrobuoni, G. (2006): "Do better-informed workers make better retirement choices? A test based on the Social Security Statement," manuscript, Princeton University.

Myers, R.J. (1993): Social Security. Fourth Edition. Pension Research Council and University of Pennsylvania Press.

Phelan, C. (1999): "Anticipation effects of looming public-pension reforms: A comment." Carnegie-Rochester Conference Series on Public Policy, 50 161-164.

Reimers, C., and M. Honig (1993): “The Perceived Budget Constraint under Social Security: Evidence from Reentry Behavior,” Journal of Labor Economics, 11 184-204.

Reimers, C., and M. Honig (1996): "Responses to Social Security by Men and Women: Myopic and Far-Sighted Behavior," Journal of Human Resources, 31-2 359-382.

Rust, J. (1994): "Structural Estimation of Markov Decision Processes," in R. Engle and D. McFadden (eds.) Handbook of Econometrics, Vol. 4, 3082-3139, North Holland.

Rust, J. (1996): "Numerical Dynamic Programming in Economics," in Handbook of Computational Economics. H. Amman et al. (eds.). Amsterdam: Elsevier.

Rust, J., and C. Phelan (1997): "How Social Security and Medicare Affect Retirement Behavior in a World of Incomplete Markets," Econometrica, 65 781-831. 
Song, J.G. (2004): "Evaluating the Initial Impact of Eliminating the Retirement Earnings Test," Social Security Bulletin, 65-1 1-15.

Song, J.G., and J. Manchester (2006): "New Evidence on Earnings and Benefit Claims Following Changes in the Retirement Earnings Test in 2000," ORES Working Paper Series 107.

SSA-S (various years): Annual Statistical Supplement to the Social Security Bulletin. http://www.ssa.gov/policy/docs/statcomps/supplement/.

SSA-H: Social Security Handbook. Online Version. http://www.ssa.gov/OP_Home/handbook/ssa-hbk.htm.

SSA-M: Program Operations Manual System (POMS). Public Version. https://s044a90.ssa.gov/apps10/poms.nsf/aboutpoms.

Taber, C.R. (2000): "Semiparametric Identification and Heterogeneity in Discrete Choice Dynamic Programming Models," Journal of Econometrics, 96 201-229.

Votruba, M. E. (2003): “Social Security And Retirees’ Decision to Work," manuscript, Case Western Reserve University.

Vroman, W. (1985): "Some Economic Effects of the Retirement Test," in Research in Labor Economics, Vol. 7. JAI Press.

van der Klaauw, W., and K.I. Wolpin (2005): "Social Security, Pensions and the Savings and Retirement Behavior of Households," manuscript. University of North Carolina-Chapel Hill. 